\title{
O CORPO E A GEOPOLÍTICA DA TECNOCOLONIZAÇÃO, TECNOCOLONIALIDADE DO CORPO na Arte, na Cultura e na Educação! (1a Parte)
}

\author{
¡EL CUERPO Y LA GEOPOLÍTICA DE LA TECNOCOLONIZACIÓN, \\ TECNOCOLONIALIDAD DEL CUERPO en el Arte, la Cultura y la \\ Educación! (Parte 1)
}

\section{THE BODY AND GEOPOLITICS OF TECHNOCOLONIZATION, TECHNOCOLONIALITY OF THE BODY in Art, Culture and Education!
(Part 1) TECHNOCOLONIALITY OF THE BODY in Art, Culture and Education!
(Part 1) \\ Marcos Antônio Bessa-Oliveira ${ }^{1}$}

Resumo: O corpo ocidental vive hoje sob o império emergente da tecnologia virtual. Na arte, nas diferentes linguagens; na produção do conhecimento, em ambientes formais ou informais da Educação e em contextos socioculturais diversos. Considerando a construção do corpo, nas artes e na educação, subjacente ao pensamento moderno europeu, sempre, da pré-história à contemporaneidade, esse está vinculado a "tecnologias" para atualização em contextos/situações diversas. A tecnologia tem atuado compondo corpos "andrógenos", "tecnológicos", "transumanos" (BRETON, 2015), "corpomídia” (KATZ; GREINER, 2005), entre outros corpos que usam da tecnologia para autoconstrução/autorreconhecimento ou construções/reconhecimentos em contextos múltiplos. Já a Era Digital como recurso "tecno(lógico)" (RODRIGUES; BESSAOLIVEIRA, 2019a) no corpo é recente (20/30 anos graças a internet) que o controle sobre os

\footnotetext{
${ }^{1}$ Marcos Antônio Bessa-Oliveira é Professor na UEMS (nas Graduações em Artes Cênicas, Dança e Teatro e no PROFEDUC), é Coordenador do NAV(r)E - Núcleo de Artes Visuais em (re)Verificações Epistemológicas - UEMS/CNPq. ORCID iD: https://orcid.org/0000-0002-47837903. Email: marcosbessa2001@gmail.com.
} 
“corpos primitivos" (RODRIGUES; BESSA-OLIVEIRA, 2019a) se dão; corpo primitivo é Préhistória e corpo tecnológico modernidade. Da submissão do corpo à tecnologia, das pedras às redes sociais, discutirei um corpo na arte e na educação que subjaz a colonialidade tecnológica. Um corpo sob o controle tecnológico, mas sem ser "tecno(lógico)", porque quer voltar a ser um "corpo primitivo" (RODRIGUES; BESSA-OLIVEIRA, 2019a) que reconhece a tecnocolonização (BESSA-OLIVEIRA, 2019) do corpo no século XXI que escapa à virtualização/desnaturalização de si, mas que não escapa à tecnocolonialidade que virtualiza o corpo da arte e da educação. Se a virtualização ressalta a exposição do corpo na arte, por meio da imagem ex-posta nas redes sociais, de outra perspectiva a "exposição" corpórea apaga a diferença colonial dos corpos da arte na educação, por exemplo. Logo, expondo-se ou impondo ao corpo a condição de exposição ou de adestramento, o corpo contemporâneo e a geopolítica, por meio da tecnocolonização do corpo, é a tecnocolonialidade que provoca a tecno(lógica) de corpos da exterioridade que não vivem submissões/situações tecno(lógicas) dessa geopolítica. Para contemplar este debate, lanço mão de ideias de retribalização/renaturalização conscientes, por via da corpo-política (MIGNOLO, 2017) que nem a biopolítica foucaultiana contemplou, para desmontar a tecno(lógica) moderna.

Palavras-Chave: Corpo; Arte; Educação; Tecnocolonialidade; Geopolíticas.

Resumen: El cuerpo occidental vive hoy bajo el imperio emergente de la tecnología virtual. En el arte, en diferentes lenguajes artísticos; en la producción de conocimiento, en ambientes formales o informales de Educación y en diversos contextos socioculturales. Teniendo en cuenta la construcción del cuerpo, en las artes y en la educación, subyacente al pensamiento europeo moderno, siempre, desde la prehistoria hasta la contemporaneidad, está vinculado a las "tecnologías" para la actualización en diferentes contextos / situaciones. La tecnología ha estado componiendo "andrógenos", "tecnológicos", cuerpos "transhumanos" (BRETON, 2015), "corpomedia" (KATZ; GREINER, 2005), entre otros organismos que utilizan tecnología para autoconstrucción / auto-reconocimiento o construcciones / reconocimientos en múltiples contextos. La Era Digital como recurso "tecno(logico)" (RODRIGUES; BESSA-OLIVEIRA, 2019a) en el organismo es reciente (20 / 30 años gracias a Internet) que controlan sobre los "cuerpos primitivos" (RODRIGUES; BESSA-OLIVEIRA, 2019a) se llevan a cabo; cuerpo primitivo es la Prehistoria y el cuerpo tecnológico es la modernidad. Desde la sumisión del cuerpo a la tecnología, desde las piedras hasta las redes sociales, discutiré un cuerpo en el arte y la educación que subyace a la colonialidad tecnológica. Un cuerpo bajo control tecnológico, pero sin ser "tecno(logico)", porque quiere volver a ser un "cuerpo primitivo" (RODRIGUES; BESSAOLIVEIRA, 2019a) que reconoce la tecnocolonización (BESSA-OLIVEIRA, 2019) del cuerpo en el siglo XXI que escapa a la virtualización / desnaturalización de sí mismo, pero que no escapa a la tecnocolonialidad que virtualiza el cuerpo del arte y la educación. Si la virtualización resalta la exposición del cuerpo en el arte, a través de la imagen ex-puesta en las redes sociales, desde otra perspectiva, la "exposición" corpórea borra la diferencia colonial de los cuerpos en el arte en la educación, por ejemplo. Por lo tanto, al exponer o imponer al cuerpo la condición de exposición o entrenamiento, el cuerpo contemporáneo y la geopolítica, a través de la tecnocolonización del cuerpo, es la tecnocolonialidad que causa el tecno(logica) de los cuerpos del exterior que no viven sumisiones / situaciones tecno(logicas) de esta geopolítica. Para contemplar este debate, utilizo

Cadernos de estudos culturais, Campo Grande, MS, v. 2, p. 161-184, jul./dez. 2020. 
ideas de retribalización / renaturalización consciente, a través del cuerpo-política (MIGNOLO, 2017) que ni siquiera la biopolítica foucaultiana contemplaba, para desmantelar el tecno(logica) moderno.

Palabras claves: Cuerpo; Arte; Educación; Tecnocolonialidad; Geopolítica.

Abstract: The Western corps lives today under the emerging empire of virtual technology. In art, in different languages; in the production of knowledge, in formal or informal environments of Education and in diverse sociocultural contexts. Considering the construction of the body, in the arts and in education, underlying modern European thought, always, from prehistory to contemporaneity, it is linked to "technologies" for updating in different contexts/situations. The technology has been composing "androgen", "technological", "transhuman" bodies (BRETON, 2015), "corpomedia" (KATZ; GREINER, 2005), among other bodies that use technology for selfconstruction/self-recognition or constructions/recognitions in multiple contexts. The Digital Age as a resource "techno(logical)" (RODRIGUES; BESSA-OLIVEIRA, 2019a) in the body is recent (20/30 years thanks to the internet) that control over the "primitive bodies" (RODRIGUES; BESSA-OLIVEIRA, 2019a) take place; Primitive body is Prehistory and technological body modernity. From the submission of the body to technology, from stones to social networks, I will discuss a body in art and education that underlies technological coloniality. A body under technological control, but without being "techno(logical)", because it wants to return to being a "primitive body" (RODRIGUES; BESSA-OLIVEIRA, 2019a) that recognizes the technocolonization (BESSA-OLIVEIRA, 2019) of the body in the 21st century that escapes the virtualization/denaturalization of itself, but that does not escape the technocoloniality that virtualizes the body of art and education. If virtualization emphasizes the exposure of the body in art, through the image ex-posted on social networks, from another perspective the body "exposure" erases the colonial difference of the bodies of art in education, for example. Therefore, exposing or imposing on the body the condition of exposure or training, the contemporary body and geopolitics, through the technocolonization of the body, it is the technocoloniality that provokes the techno(logic) of bodies of exteriority that do not live in submissions/techno(logical) situations of this geopolitics. To contemplate this debate, I use conscious retribalization/renaturalization ideas, through the political-body (MIGNOLO, 2017) that even Foucaultian biopolitics did not contemplate, to dismantle modern techno(logic).

Keywords: Body; Art; Education; Technocoloniality; Geopolitical.

\section{DESABAFO-MANIFESTO-Denuncia ${ }^{2}$}

${ }^{2}$ Uma primeira versão deste artigo foi apresentada no II Congresso Internacional Online de Estudos sobre Culturas, na modalidade online, 2019. Este texto é a $1^{\text {a }}$ Parte de uma reflexão sobre o corpo e a tecnocolonialidade na arte, na cultura e na produção de conhecimentos em desenvolvimento para a composição de um livro. O texto contempla uma discussão que foi

Cadernos de estudos culturais, Campo Grande, MS, v. 2, p. 161-184, jul./dez. 2020. 
As Américas estão se preparando para entrar no século 21 com quase as mesmas desigualdades do século XIX. Mas, ao contrário de então, eles não o farão separados por caminhos diferentes, mas como pares da mesma ordem mundial em que os Estados Unidos ainda ocupam o lugar primata e a América Latina um lugar subordinado e afetado pela crise mais grave de sua história pós-colonial (QUIJANO, 2019, p. 149, tradução livre minha).

A epígrafe deste texto pertencente a Aníbal Quijano, ainda que grassada do texto "La americanidad como concepto o América en el mundo modernocolonial" republicado em 2019, é, na verdade, do texto do mesmo autor - "La americanidad como concepto, o América en el moderno sistema mundial" originalmente publicado no ano de 1992. Entretanto, passados vinte anos da entrada das Américas no século XXI, ainda que ocorridos quase 30 anos da publicação primeira do texto, a atualidade da desgraça trazida pelo enunciado epigráfico de Quijano parece que aquele foi escrito em tempos de COVID-19. ${ }^{3}$ Ora vejam: adentramos ao contexto enunciado por Quijano com desigualdades iguais, se não maiores, que as colocadas para as Américas em situação de "descobrimentos". Assertivamente, não fomos sequer separados pela condição de pandemia que se colocou igualmente para todos os países americanos, ainda que não sejamos hoje Américas iguais, após o dia 16 de março de 2020. Somos "pares" das mesmas desgraças trazidas pelo vírus - adoecimento, internações e mortes em larga escala, especialmente nas duas localidades que se viram supostamente imunes ao vírus graças à arrogância de seus dirigentes -, entretanto, acometidos, mais uma vez, pelas grandes diferenças provocadas pela colonialidade do poder (QUIJANO, 2019) desde, também juntos, 1500. Logo,

desenvolvida enquanto projeto de Pós-doutoramento em Estudos de Linguagens (FAALC-UFMS) (março/2019 à março de 2021), acerca de uma História da Arte Outra para a América Latina, intitulado "Arte, Cultura e História da Arte Latinas na Frontera: "Paisagens", Silêncios e Apagamentos em Cena nas "Práticas Culturais" Sul-Mato-Grossenses" que é vinculado ao Grupo de Pesquisa NAV(r)E - Núcleo de Artes Visuais em (re)Verificações Epistemológicas CNPq/UEMS.

${ }^{3}$ Vou tratar adiante mais a fundo desta questão, mas aqui cabe elucidar que estou argumentando comparativamente que tanto a entrada das Américas no século XXI que anunciava a crise da "modernidade", alertada por Aníbal Quijana, como a situação de pandemia pela COVID-19 que expõe a crise das políticas na atualidade, estourada no Brasil em meados do primeiro trimestre de 2020, porque ambas estão acercadas da colonização que é a raiz da colonialidade e do que vou tratar como tecnocolonialidade.

Cadernos de estudos culturais, Campo Grande, MS, v. 2, p. 161-184, jul./dez. 2020. 
agora mais que nunca, submissos às agruras trumpianas que se alarmam em condição privilegiada daquele, não bastassem a equivocada política econômica e de ódio e de aglomeração defendidas, o Bolsominion brasileiro ainda nos submete à suposta (e muito improvável) comparação aos estadunidenses. Ainda é assertivo no texto de Quijano o fato de que, se não a pior, a crise apresentada ao mundo pela COVID-19 ter se e ser, até o momento (sabemos que daqui para frente que não é a última), tornado a mais grave em nível mundial, mas que, certamente, demonstravam os números em 09 de maio deste presente, o será ainda pior nos países que hoje ocupam o bloco definido na história como América Latina. Obviamente considerando a lógica comparação impossível aos países da Europa, mas, do mesmo modo, porque estamos tendo o equívoco político brasileiro de seguir os pronunciamentos primatas do líder estadunidense (lunático, diga-se de passagem) como se fossem aplicáveis, por encontrar situações, iguais ou melhores, em terras brasileiras para simplesmente aqueles poderem ser aplicados. Ora pois! Diriam os portugueses. A "boa" da verdade é que o "líder" (ditador, sanguinário e demagogo) brasileiro continua agindo, nos casos relacionados à COVID-19, bem como em relação à "política" econômica brasileira (hoje, opostamente às ideias até do maluco Donald Trump em relação a um ou outro caso), considerando os corpos brasileiros - agora, $12 \mathrm{~h} 10 \mathrm{~min}$ do dia 09 de maio de 2020, quase 10 mil mortos - como descartáveis e, porque não dizer, os cidadãos e cidadãs brasileiros/as como corpos matáveis. Mas esses corpos que estou preferindo argumentar sobre, os vários corpos brasileiros mortos em virtude, direta ou indiretamente (os números ociosos e mal controlados pelas Secretarias e pelo Ministério de Saúde têm mostrado a imprecisão dos dados oficiais relacionados tanto aos novos casos quanto em relação às mortes pelo vírus (VIDA E AÇÃO, 2020, online)), pela COVID-19, não estão nos corpos elencados por Achille Mbembe (2016), ao menos naquele contexto de argumentação da "Necropolítica", considerando que aquele autor ainda pensa nos corpos sociológicos, no máximo etnológicos, com base teórica da/na Europa. Enquanto estou querendo privilegiar os corpos considerados inumanos, racializados pela presença do colonialismo histórico também, mas mais pela imposição da colonialidade do poder que subjaz sobre e sob a noção de política e de Estado no contexto brasileiro. Ao certo, portanto, matáveis são os corpos que não tem "histórico de atleta", que se acometeram de uma "gripezinha" ou de um "resfriadinho" porque são corpos frágeis e descartáveis das políticas econômicas desse momento de desgoverno do Brasil (cf. PRESIDÊNCIA DA REPÚBLICA, 
2020, online). São corpos, por conseguinte, "sem" história, "sem" memória, "sem" conhecimento, portanto, sem alma e que não fazem parte do padrão estabelecido, agora, por aquele que se coloca, supostamente, acima da lei e de todos. Caem ministros, empossa-se "policiais", caem "policiais", empossa subsecretário, caem subsecretários, entre outras tantas desgovernanças do desgoverno, o fato é que, "na história da política do país", nunca se viu tantas mortes embaladas pelo discurso daquele que se diz dirigente/soberano do Brasil "eleito" pela maioria "democraticamente". A nossa velha história pós-colonial, ainda na brisa (ou na tempestade) da epígrafe quijaniana, têm vindo à tona no Brasil que desce a ladeira desgovernadamente diuturna e constantemente: a velha política do "toma lá, dá cá"; discursos de exaltação da Ditadura Militar e fim dos poderes legisladores; família e amigos acima de todos; "terrivelmente" religiosos sobre as certezas das leis e da ciência, além de muitas coisas já ocorridas e aqui escapadas (graças à agilidade das merdas que se diz), entre as muitas que, tenho certeza, ainda virão; a pandemia (válvula e estopim das loucuras do desgoverno) ainda não tem data pré-definida para seu fim. Em meio à pandemia que achou lugar confortável na política de corpos a morrer do Estado-nação, vemos aumentar, a cada dia, o primeiro colonialismo histórico brasileiro: o desgoverno age como se fosse o "descobridor" das Américas impondo as suas descabidas regras que vão contra todas as orientações municipais, estaduais e da OMSOrganização Mundial da Saúde - orientações que não eram reforçadas nem pelo seu mais novo ex-Ministro da Saúde (Nelson Teich deixou o cargo na sexta-feira (15/05) (ANDRADE, 2020, online), como se colocava o seu antecessor, Luiz Henrique Mandetta (demitido na quinta-feira (16/04) (SHALDERS, 2020, online)) -, cometendo genocídios diários assim como fizeram os colonizadores na chegada às Américas na maioria dos casos. De modo contraditório também, a despolítica (BESSA-OLIVEIRA, 2020) do Governo Federal age contra tudo e todos os que se colocam contrários às suas ações para liberação de uma economia para a morte desses corpos matáveis enquanto a saída, única e plausível, é o distanciamento social. Brigas homéricas como políticos seus partidários e com contrários também, o despresidente da República se coloca soberanamente,

\footnotetext{
4 Desde que tomou posse, o Presidente da República tem empossado e desempossado, de Secretários a Ministros, demonstrando a desgovernança pela qual o país passa. Mais recentemente, inclusive, o senhor Presidente tem deixado claro que, mais ou menos assim, aquele que não for submisso a ele não fica no governo.
}

Cadernos de estudos culturais, Campo Grande, MS, v. 2, p. 161-184, jul./dez. 2020. 
ditador, com punhos de ferro de quem assina a última ordem, contra os corpos brasileiros que precisam de incentivo à vida e não à morte como tem reforçado a despolítica da economia da morte do desgovernante brasileiro. Todos os dias, de 16 de março até então, o velho colonialismo/coronelismo tem se colocado travestindo-se no corpo assassino para literalmente matar mais de vinte mil brasileiros e brasileiras, até agora, impondo sua política do "toma lá, dá cá" fazendo barganha de cargos e cabeças com o chamado "Centrão"; donos da velha política - para reforçar seu poder ditatorial. Assim o desgoverno tem incentivado a busca pela morte daqueles/daquelas brasileiros e brasileiras que sequer sabem que são apenas míseros e míseras corpos que morrem para o Estado atual de segregação. Enquanto a história de país colonizado é reforçada por mais de quinhentos anos, não bastasse aquela, agora uma política que escancara o poder do desgoverno na cara dos brasileiros, faz valer a insanidade de uma parcela lunática brasileira que o elegeu, demonstrando na pessoa do Presidente (aquele sim inumano) uma colonialidade do poder centrada em suas ideologias (partidárias, religiosas, de família, de gênero, raça e classe), ações, despolíticas e discursos de ódio contra tudo e todos. Enquanto muitos dos/das brasileiros e brasileiras que morrem não têm onde sepultar os "seus" corpos matados pelo ditador, o Presidente que desgoverna o Brasil faz churrasco fake (contra a imprensa) ou anda de Jet Ski no Lago de Brasília para manter a forma de histórico de atleta. Os milhares de corpos brasileiros mortos pelos posicionamentos do desgoverno diante da pandemia da COVID-19 com sua economia da morte são, na sua grande maioria, cidadãos e cidadãs (alguns até podem ter votado na situação, e, provavelmente, agora estão arrependidos) que sobrevivem às margens de todos os discursos e ações, que deveriam ser benesses, das políticas. Logo, o contrário do que ocorre com esses indivíduos agora na atual situação precária em que nos encontramos. "Na perspectiva americana do futuro, certos processos merecem ser postos em relevo" (QUIJANO, 2019, p. 149, tradução livre minha) ${ }^{5}$. Sendo, portanto, um dos primeiros, na minha perspectiva, a manutenção da história póscolonial do Brasil, mas, conjuntamente a esta, já que são indissociáveis na perspectiva de Aníbal Quijano, a presença, cada vez maior, da colonialidade do poder em um local como o Brasil, que está, sempre na história e ainda hoje

\footnotetext{
5 "En la perspectiva americana del futuro, ciertos procesos merecen ser puestos en relive" (QUIJANO, 2019, p. 149).
} 
constantemente, sob a imposição de discursos e ações - ou invejando e copiandoos (como fazem todos - da Presidência, passando pelo Ministério da Internacionalização, no Ministério da Economia, do Meio Ambiente, no Ministro da Educação em pessoa, até à Secretaria Especial que não representa, mas se diz, da Cultura, e, parece ser um consenso do desgoverno como um todo) -, dos projetos hegemônicos e igualmente genocidas do mundo ocidental.

A colonialidade é um dos elementos constituintes e específicos do padrão mundial do poder capitalista. Baseia-se na imposição de uma classificação racial/étnica da população mundial como a pedra angular desse padrão de poder e opera em cada um dos planos, campos e dimensões materiais e subjetivos da vida cotidiana e em escala social (QUIJANO, 2019, p. 151, tradução livre minha) ${ }^{6}$.

É, neste sentido, mais uma vez apresentado por Aníbal Quijano, o de classificação social com base em racialização ou etnicidade do diferente, que o desgoverno brasileiro tem se colocado como o genocida do século perante a pandemia da COVID-19 com sua despolítica de economia da morte em contraposição a uma corpo-política (MIGNOLO, 2017a) que luta pela vida. Por economia da morte, obviamente, estou considerando as políticas econômicas do atual desgoverno, que mesmo que ruins ainda são mal aceitas pelo seu Ministro da Economia, as estabelecidas desde o "abono emergencial" de $\mathrm{R} \$ 600,00$ que levou a população brasileira menos ou com nenhuma assistência do Governo - os cidadãos e cidadãs invisíveis - a enfrentar filas quilométricas sob dias de sol ou chuvas, com enchentes em alguns lugares, noites frias e, pior, por horas e horas, quando deveriam estar em casa ou no mínimo distantes um do outro ao menos um metro e meio como recomendações de quem luta pelas vidas alheias. Mas também me é política econômica da morte o fato desse desgoverno importa-se mais com a situação econômica durante e após a pandemia, levando ao STF - Supremo Tribunal Federal - empresários e políticos milionários, ou no mínimo muito ricos e de muito boa vida financeiramente - para quem não faltaria um respirador, um leito de UTI-Unidade de Tratamento Intensivo particular, menos ainda para àqueles que não faltariam equipamentos de proteção individual, as EPIs, de belas

\footnotetext{
6 "La colonialidad es uno de los elementos constitutivos y específicos del patrón mundial de poder capitalista. Se funda en la imposición de una clasificación racial/étnica de la población del mundo como piedra angular de dicho patrón de poder, y opera en cada uno de los planos, ámbitos y dimensiones, materiales y subjetivas, de la existencia cotidiana y a escala social” (QUIJANO, 2019, p. 151).
}

Cadernos de estudos culturais, Campo Grande, MS, v. 2, p. 161-184, jul./dez. 2020. 
marcas importadas: afinal, eles já andavam de carros blindados $100 \%$ distanciados do resto da população. Ainda contempla minha lógica de economia da morte o fato do Ministro da Economia do atual desgoverno desvalorizar, generalizadamente, o Funcionalismo Público brasileiro como se o país fosse uma máquina industrial qualquer que trabalhasse apenas com a injeção de combustível fóssil. Vários são os ataques desse senhor em relação aos funcionários públicos brasileiros. Não escapa, portanto, ao abrigo da economia da morte bolsominian o fato do Presidente da República desconsiderar as orientações governamentais (estaduais e municipais) e provocar aglomeração, ainda que dos seus apoiadores que o são par de igualdades (na ignorância), ainda, também, que sem consciência de suas inferioridades para o desgovernante, sem o uso de EPIs, para defender uma suposta política econômica que está provocando as mortes hoje no Brasil com números alarmantes cada dia mais. Nesse sentido, é também característica da economia da morte o fato do desgoverno "ofertar" auxílio aos Estados da Federação que estão às mínguas por causa da pandemia, mas, para isso, barganhar, em troca, mais e mais, "contrapartidas", dos funcionários públicos de diferentes categorias - como se fossemos agora culpados pela disseminação do vírus -, para que esta esmola, a troca de política, chegue a cada um deles. Igualmente faz parte da economia da morte da política atual, e que de modo claro contempla melhor minha argumentação de existência, reforço e manutenção cotidiana dela, o fato do inescrupuloso Presidente amenizar as mais de dez mil mortes (ao dia desse escrito) de brasileiros e brasileiras dizendo que esses e essas são números já esperados e que, “'Ô, cara, quem fala de... Eu não sou coveiro, tá certo?', declarou Bolsonaro. O repórter, então, tentou fazer novamente a pergunta. 'Não sou coveiro, tá?', repetiu" (CORREIO 24H, 2020, online) ou que "“Alguns vão morrer? Vão, ué, lamento. Essa é a vida"' (apud MOTA, 2020, online), bem como ainda (ou melhor dizer mal como) disseram também outros do seu desgoverno (o Ministro da Economia e a também mais nova ex-Secretária Especial da Cultura - Regina Duarte que disse que “"pessoas sempre morrem'. 'Se você falar vida, do outro lado tem morte. Sempre houve tortura. Stalin, quantas mortes? Hitler, quantas mortes? Não quero arrastar um cemitério de mortes nas minhas costas. Não quero isso para ninguém"” (apud COSTOLLI; TESTI, 2020, online)) que é muito natural que alguns morreriam mesmo ou que a "vai passar rápido" no Brasil. Esses últimos, de modo claro, desde o desgovernante até os seus súditos e leais seguidores subordinados, inumanos, tratam as vidas de brasileiros e brasileiras perdidas, as famílias e amigos que hoje choram as suas 
perdas irreparáveis, àqueles que carecem de todos os tipos de auxílio de um governo legítimo - logo, aqueles que mais precisam agora de no mínimo um ombro amigo, ainda que sem podermos nos abraçar - como corpos desprezáveis, matáveis e que não fazem a menor falta para sua política econômica da morte a não ser como mão de obra operária e barata. Esses posicionamentos imperativos/impositivos, por meio de ações, discursos, leis ou decretos redigidos nas madrugadas, esclarecem a colonialidade do poder sobre corpos de que fala Aníbal Quijano. Mas que agora poderia, claramente, dizer tratar-se de uma política de morte que atenta contra as vidas dos/das brasileiros e brasileiras por meio e imposição de uma economia da morte que seria também uma geopolítica da saúde, da morte, da doença e, porque não, uma geopolítica que opera contra e para escolher/selecionar o corpo matável que ainda poderá ou terá o direito porque vale mais ao trabalho - de manter a vida. Jair Messias Bolsonaro, ainda bem, garantiu, ele próprio, que não é "Messias" e que, infelizmente, (tenho que registrar que ele disse isso, não o faço, obviamente, para vangloriá-lo) “Alguns vão morrer? Vão, ué, lamento. Essa é a vida"' (apud MOTA, 2020, online) como já reportei. Em tudo isso, mais uma vez, tendo por base Aníbal Quijano, é a manutenção da história pós-colonial da América Latina, mas, igualmente, está sob a égide da colonialidade do poder que é a manutenção de um discurso que reforça a existência (quando na verdade é uma invenção dos discursos hegemônicos) de padrões de raça e etnia, mas, muito claramente, de corpo que pode ou tem o direito, ou ainda para manter o "tom", o poder de viver. E esse padrão é quem dá a face mais escura da atualidade, parafraseando Walter Mignolo (2017) em "O lado mais escuro da modernidade", que reforça e garante, ao menos pensam eles, e que dá o "direito" ao desgoverno de matar mais de 20 mil: hoje, 25 de maio de 2020 , precisamente, 23.522 mortes de brasileiros e brasileiras. A economia da morte do desgoverno tem também obrigado até mesmo o serviço de saúde brasileiro selecionar os corpos matáveis e morríveis que, como sabemos, não tem chance aqueles e aquelas que são mais velhos ou que têm já algum problema de saúde crônica que os colocam no chamado Grupo de Risco da COVID-19 que, também no Brasil, se perdeu como referência de e à morte. Essa economia da morte, por meio desse padrão de raça, étnico, sexo, quem pode ou não produzir, religioso que seleciona corpos que devem morrer e os que têm dinheiro, nem é direito de viver - age por meio da ideia de existência de um suposto padrão de corpo que, acabo de saber, não estavam nos mais de 11 mil mortos (noticiado no Fantástico às 19h14min do domingo de 11 de maio) espalhados pelo Brasil afora. O

Cadernos de estudos culturais, Campo Grande, MS, v. 2, p. 161-184, jul./dez. 2020. 
problema do Brasil, especialmente, ao adotar essa ideia equivocada da existência de um padrão de corpo ou manter e reforçar a economia da morte é que nem mesmo a saúde pública e até a privada brasileiras já não tinham condições de sequer tentar atender, para despistar, corpos que querem matar porque não contemplam àquele padrão. Logo, qual será, já está sendo, na verdade, a situação caótica da saúde pública brasileira? Respondo: literalmente matar os corpos que são morríveis na ótica da política econômica da morte em que considera que Alguns vão morrer? Vão, ué, lamento. Essa é a vida - ou "'Quem é de direita toma cloroquina. Quem é de esquerda toma Tubaína"” (apud URIBE; CARVALHO, 2020, online) - como profetisa agourando o falso messias de 2018. Contrariando à política econômica da morte alguns corpos até insistem e reexistem à morte. Mas, infelizmente, as condições para encarar uma situação que ainda está por vir, já que o Brasil não vive isoladamente dentro de supostos limites municipais e estaduais, na saúde brasileira tem previsão caótica e catastrófica. Centenas de milhares de corpos ainda poderão ser mortos pela política do desgoverno Bolsonaro. Não bastasse ainda toda essa desgraça até aqui denunciada, ainda precisamos conviver com a economia da morte que por meio das brechas no sistema de aquisição de medicamentos e equipamentos (graças ao momento de emergência ou calamidade pública por vias da pandemia que livra da burocracia) ainda fraudam as compras e aquisições de aparelhamentos para a saúde pública em todas as localidades brasileiras. Políticos, empresas, empresários ou pessoas físicas muitas vezes nem sequer ligadas à saúde, de algum modo, têm tentado (e realizado), de forma escancarada e de cara lavada, burlar e roubar as finanças públicas do Brasil como sempre fizeram na velha política que, segundo o desgovernante em plataforma de campanha, não seria o caso e nem faria parte do seu desgoverno. A opção feita pela política, mais ainda, atitudes desleais como essa (não que esteja considerando o brasileiro, num número significativo, com bom caráter - parece fazer parte do corpus do brasileiro ser ladrão e ser maucaráter), mas, à medida que o "líder" perverso do desgoverno ressalta a política de economia da morte, mais ainda os seus correligionários sentem-se no direito de matar corpos brasileiros roubando da saúde pública ou infringindo as orientações, regras e até leis de distanciamento social implementados. Por exemplo, a manutenção dessa ideia de política de economia da morte que estou desenvolvendo, reforçada pelo desgoverno desde sua campanha (armamentista, feminicida, pré-conceituosa, ancorada numa falácia de família e religião), tem mostrado que até os corpos "indígenas" e a própria natureza sofrem com tal 
campanha. Os "indígenas", historicamente, lembrando nossa condição póscolonial, sofrem desde 1500 com a colonização e, de $1^{\circ}$ de janeiro de 2019 para cá, desde que este desgoverno assumiu, têm sofrido mais ainda com a invasão de terras por grileiros de toda sorte e têm assassinados seus líderes pelos mesmos comparsas do despresidente: de políticos, por ele conduzido a cargos, e eleitos, tendo sua retaguarda, também elevados a cargos estratégicos ao meio ambiente no desgoverno, à fazendeiros e garimpeiros que ele bem e abertamente defende a fim de matar "índios" e a Natureza: "Queimar maquinário, hoje vou conversar de novo [sobre inutilização de maquinário]. Se a máquina chegou lá, ela sai", disse Bolsonaro para os garimpeiros. "Já dei a dica para vocês: se entrou, sai"" (apud BRAGANÇA, 2020, online). Os "indígenas" no Brasil são corpos matáveis desde 1500 com a chegada dos invasores europeus, mas, entretanto, nunca foram tão subjulgados a uma política econômica da morte como o são agora: para esse desgoverno "terras indígenas" são metáforas e contraditórios à sua economia de poder matar. Do mesmo jeito o pico de desmatamento e queimadas das florestas pelo Brasil afora tem quebrado recordes de janeiro de 2019 até então (Cf., por exemplo, DW, 2020, online). Logo, se o "indígena" é corpo matável porque não produz para essa ótica do corpo bom que é o corpo que produz matando, a natureza, produzindo madeira, ouro, pedras preciosas, minerais diversos, alimentos em larguíssima escala (agricultura e agropecuária, o agronegócio), entre outros recursos selvageiramente retirados dela, o bom, para essa política econômica da morte é o corpo da Natureza morto. Essa política da economia da morte, por conseguinte, toma o "indígena" e a Natureza como corpos matáveis porque na sua lógica sobrepõe o homem à Natureza, homens aos supostamente vistos como não-homens, os com alma aos sem alma, e assim sucessivamente: ou seja, ao invés de conviver com e a partir e favor da Natureza, o desgoverno prefere submetê-la às suas políticas econômicas da morte; corpo bom é corpo que produz, se não é o corpo morto (nasce com isso, também, um ódio contra tudo e todos). Mas se a política econômica da morte de Jair Bolsonaro e de seus Ministros (da Economia, da Educação, do Meio Ambiente, das Relações Exteriores, entre outros) não defende o isolamento social interno, haja vista que para ambos o mundo e o vírus tornaram-se comunistas, o distanciamento internacional parece ser para ambos também um decreto de morte para a socialização/relações globais do País. Haja vista, igualmente, a chegada do "comunicavírus" (como imbeciloidemente declarou o Ministro das Relações Exteriores no seu texto "Chegou o Comunavírus" publicado em seu Blog 
Metapolítica 17 em 21 de abril do corrente ano), em que o infelizmente Chanceler brasileiro diz que [o] mundo enfrenta 'comunavírus'. Logo, parece-me que o despresidente e seus desministros defendem e trabalham por meio de suas políticas econômicas da morte e agora também por uma política do ódio ao diferente, o distanciamento do Brasil dos seus pares na América Latina (UOL, 2020, online, às 10h34min/horários de MS), pois o Brasil ocupa, cada vez mais, o lugar de País non grato no Continente Latino-americano graças, também, o alastramento da contaminação da população brasileira pelo novo coronavírus. Contraditórios a parte, o desgoverno que se quer aproximado, a todo custo, do país da globalização (Estados Unidos), luta contra um suposto "globalismo" ideológico enraizado, aí sim, nas suas mentes ideológicas do mal: é um distanciamento às avessas. Quer dizer, fazendo uso do conceito mais atrasado de fronteiras, exclusivamente como algo que separa, as políticas da economia da morte e do ódio, do desgoverno Bolsonaro, tornaram-nos, até então, país indesejável no bloco Latino. O Brasil é hoje o país latino que tem o número de casos de COVID19 (entre mortes confirmadas e contaminados) internos maior que a soma dos casos de todos os países Latino-americanos. Não diferente, só perdemos o primeiro lugar na classificação de países que lidaram muito mal com a pandemia para os Estados Unidos (curiosamente será que é por causa dos desgovernantes de ambos?). Assim, fomos declarados indesejáveis (personas que no son bienvenidas) por todos os presidentes dos países Latinos (Fantástico, 10/05/2020) e, mais recentemente, tivemos, no melhor sentido do pré-conceito de fronteira, as portas fechadas (ou poderíamos metaforicamente pensar nos muros mexicanos) ATÉ nos Estados Unidos, inclusive para cidadãos europeus ou norteamericanos que passarem pelo Brasil. Triste trópicos! O brasileiro sempre se viu como o mais forte no bloco Latino-americano. Ledo engano nos mostra a pandemia! Re-existentes e insistentes nesta situação toda são os corpos dos profissionais da saúde brasileira. Esses sim verdadeiros salvadores da Pátria! Em muitos casos, na maioria deles e lugares, os profissionais de saúde encontram falta dos EPIs, para não dizer de quase tudo, bem como morrem acometidos do vírus COVID-19 para o qual estão ali para tentar tratar/salvar. São milhares já afastados com a doença confirmada, muitos mortos com o vírus, outros tantos milhares que não podem estar, mas alguns ainda insistem e persistem por amor à profissão e ao próximo, na linha de frente no atendimento aos corpos descartados (descartáveis) e matáveis da política econômica da morte porque pertencem aos prováveis do Grupo de Risco ou por estarem entre os que são perversamente contemplados pela 
política do ódio. E era quase uma centena de profissionais de saúde já mortos pela COVID-19 no Brasil em 06 de maio deste ano (G1, 2020, online). Já em 05 de maio o "Brasil ultrapassa [os] EUA em mortes de profissionais de Enfermagem por Covid-19" (CONFEN, 2020, online). A política econômica da morte mata até àqueles que poderiam salvar vidas. Pois, quanto mais o desgoverno amplia por decreto o hall de atividades essenciais no país (abrindo igrejas, salões de beleza, oficinas mecânicas, bares, entre outros serviços necessários, mas não essenciais, que têm por trás as suas políticas de morte e de ódio amparadas pelos seus seguidores (tem quase 3 meses que não faço barba ou cabelo), a fim de fazer a economia girar, mais a população se sente motivada e motivacionada pelo líder, e até obrigada - já que seus postos de trabalhos abrem-se - a irem para as ruas para trabalhar, sobreviver e, por conseguinte, tornarem-se vulneráveis e/ou vítimas, sem saber, da política de economia da morte do desgoverno. Em um país onde a política de sobrevivência é o trabalho, para consumir e poder ter e sobreviver, a política econômica de morte e a política do ódio ao próximo diferente funcionam muito bem: acham lugares aninhadores. O desgoverno tem aberto as portas aos trabalhadores, via decretos, mas os têm, igualmente e em grau absurdo de perversidade, tornado-os corpos que podem ser matados! Será que ninguém ainda viu isso? Isso tem que ser considerado crime de morte contra a humanidade!? A política econômica da morte do desgoverno está baseada no controle material e da subjetividade desses corpos, razão e emoção, bem como sinaliza o poder da colonialidade sobre os corpos, trabalho, raça, classe, gênero, sexo e religião já também observados por Aníbal Quijano (1992). Primeiro o discurso do desgoverno empenha-se em reforçar a maior importância da economia ou do trabalho como ponto principal para a recuperação não apenas da economia, mas igualmente coloca em risco a saúde brasileira sob a alegação de que "Não podemos ter um remédio que [no] final das contas a dose vai ser tão grande que o número de problemas vai ser muito maior que o vírus em si. É questão de bom senso"" (apud FERNANDES, 2020, online). Assim, o desgoverno provoca a debandada para as ruas, a fim de retomar a política da economia da morte, impondo a materialidade do trabalho como foco dos corpos que podem ser matáveis. Igualmente, ainda nesse seguimento do material sobre o subjetivo, o desgoverno reforça que

'Não podemos agir dessa maneira irresponsável. Que o vírus vem, mais forte ou mais fraco, ele vem. É igual uma chuva. Se ela vai aparecer, você vai se molhar e toca o barco. Você não pode é simplesmente se esconder, se enclausurar e dizer:

Cadernos de estudos culturais, Campo Grande, MS, v. 2, p. 161-184, jul./dez. 2020. 
'vou ficar de quarentena três, vinte, não sei quantos dias em casa, e tá tudo bem'. Tudo bem, não. Não é assim' (apud FERNANDES, 2020, online).

Afinal, "Vai morrer gente? Vai morrer gente"” (apud FERRO, 2020, online)! Para o desgoverno parece não haver jeito e nem saída para a crise instalada com a pandemia. Não há saúde pública no Brasil?! Por conseguinte, fica sob o controle dessa política econômica da morte a subjetividade desses corpos que podem morrer. Pois, ao romper e burlar as imposições impostas pelos governos estaduais e municipais, indo à padarias, à farmácia sem precisão clínica, o desgovernante brasileiro dá aos corpos matáveis as mesmas prescrições anti-científicas e premissas para saírem do isolamento social. Prova disso é o aumento na redução constante dos índices que demonstram o nível de isolamento social nas cidades. E que, do mesmo jeito, é comprovado pelo crescente número dos que comungam de manifestações pró-morte (ainda que, felizmente, dos seus pares sociopatas) ao conceito de inumanos (bolsominions) sem máscaras e sem manterem, no mínimo, o distanciamento necessário recomendado pelos órgãos de saúde. Esses controles, portanto, estão na lógica do controle por meio da colonialidade do poder sobre os corpos das diferenças que foram racializados e etnicizados pela colonização histórica e que se mantém como o padrão para definição hoje ainda de quem e como se têm o poder. E, não diferente, o agenciamento desse controle das materialidades e subjetividades dos corpos descartáveis, por meio da política econômica da morte, dá-se em diferentes níveis do sistema social definido, também, pelo padrão de poder colonial. Controle do corpo! Controle das almas! Controle do trabalho! Controle ao acesso! Controle de quem vive e controle de quem deve morrer! Não difere muito de todo este ponto, por certo, o ódio emanado do Palácio do Planalto - do Gabinete da Presidência - em Brasília pela política do ódio em relação aos corpos - materiais e subjetivos - que estão morrendo pela COVID-19 porque não podem trabalhar para manter a máquina. Aliás, às 18h43min (horário de Mato Grosso do Sul) os indivíduos, brasileiros e brasileiras - cada qual com seu nome e registro (imaginemos àqueles que são invisíveis: sem CPFs, RGs, Certidões de Nascimentos, entre outros que não são portadores de documentos oficiais (claramente declarados mortos ou inexistentes)) -, que não são apenas corpos numéricos mortos, já passavam de 13.149 vítimas da COVID-19. A tradicional insistência genocida do desgovernante em privilegiar a política da economia da morte em contrário à política pela vida desses corpos mortos, continua acontecendo na ameaça de troca do seu corpo de também despolíticos, só tenho a debochar desses bolsominions 
que acreditaram um dia nesse "falso messias" pela opção de fazer parte do conluio, avisando que todos têm obrigação de concordar com suas políticas, a econômica da morte e a do ódio, sobre os corpos já mortos e têm que ter obediência ao seus comandos para poder continuar matando, seja com "cloroquina", seja com "Tubaína". Entretanto, ao menos até agora, estão à salvo, dessas duas políticas, os familiares e os amigos do desgovernante brasileiro que vendeu a imagem, desde sempre, de família heteronormativa como padrão. Mas isso nem nos é surpresa, haja vista que era muito previsível que sua despolítica estava, desde sempre, para o padrão homem, branco, de classe alta e cristão no qual ele e os seus pensam pertencer. A pergunta que vai ficando de isso tudo é, já que não vai mesmo parar por aqui, Vai morrer gente? Vai morrer gente, até quanto vamos continuar com a história pós-colonial brasileira, iniciada em 1500 , matando corpos das diferenças culturais, coloniais e corpóreas brasileiras? Mas antes de caminhar para um encerramento, ainda que provisoriamente, deste desabafo/manifesto/denuncia, por último, mas nada menos importante, o que dizermos dos corpos da Educação brasileira que, também em tempos de COVID19, estão "paralisados" - quase sendo mortos com a manutenção até bem pouco tempo das datas regulares do Enem como se nada estivesse acontecendo -, por determinação (política e de segurança sanitária de professores e estudantes), desde o dia 16 de março de 2020? E este ponto tem fundamental importância com as questões aqui ressaltadas, da reverberação e manutenção da política da economia da morte e com a política do ódio do desgoverno Bolsonaro! Primeiro porque ambas as políticas querem, agora, matar os corpos morríveis também no acesso à Educação em Universidades Públicas ou Privadas. Já volto a este ponto! Pois, afinal, para quê dar Educação aos corpos que não precisam ficar vivos? Mas o segundo ponto tem relação com a premissa, quase primeira, deste trabalho; o corpo e a geopolítica da tecnocolonização, tecnocolonialidade do corpo na arte, na cultura e na Educação. Este é coerente com as questões porque o trabalho vai articular-se entre essas questões propriamente ditas enquanto um corpo que sobrevive à tecnocolonização, mas, infelizmente, nem sempre consegue livrar-se da tecnocolonialidade geopolítica da atualidade: a exemplo de fake news e as chamadas redes sociais que de sociais não têm nada. Mas também do acesso às tecnologias e a falta dele. Portanto, Enem, Educação, corpo e tecnologia - esses pensando nas políticas da economia da morte ou de ódio atuais - vinculam-se, em plena pandemia, exatamente porque o ministério (i)rresponsável pela Educação brasileira insistiu, até onde pode e não pode, na manutenção das datas de 
realização do Exame Nacional do Ensino Médio (Enem-2020). Mesmo sabendo que milhões de estudantes brasileiros e brasileiras não têm acesso às tecnologias digitais mesmo fora de situação pandêmica; imaginemos, pois, agora em que as aulas estão, no maior esforço e realização de um melhor trabalho possíveis, sendo desenvolvidas à distância via "tecnologias". Antes da suspensão pelo Senado Federal da realização do Enem, o ministro da Educação, Abraham Weintraub, confirmava, em 17 de maio, durante live em uma rede social, a manutenção de realização do Exame Nacional do Ensino Médio (Enem), na versão imprensa, com as datas das provas previstas para os dias $1^{\circ}$ e 8 de novembro. "Segundo ele, até lá, a quarentena já terá passado e não há motivo para o adiamento do exame" (apud ESTADO DE MINAS, 2020, online, grifos do jornal). Sorte nossa prevalecer a sanidade, ainda que muitas vezes posta sob suspeição, no Senado Federal Brasileiro acerca da questão que fez, na mesma empáfia, o desministro voltar atrás e fez mudanças na insana mentalidade do Ministro: "O Ministério da Educação (MEC) decidiu adiar o Exame Nacional do Ensino Médio (Enem) 2020 em função dos impactos da pandemia do novo coronavírus. 'As datas serão adiadas de 30 a 60 dias em relação ao que foi previsto nos editais [...]"” (AGÊNCIA BRASIL, 2020, online). Nesse sentido, torna-se evidente que o desgoverno, por meio dos seus, insiste na matança de corpos que não querem ter que viver submissos à tecnocolonização, mas, infelizmente, vou tentar deixar claro no texto que segue, (ainda que nas partes futuras a serem publicadas em suportes diferentes deste), são corpos que não conseguem viver sem ser subjacentes à geopolítica da tecnocolonialidade que para mim é um dos artifícios da colonialidade do poder tratada também por Aníbal Quijano (2019) mais uma vez. Quer dizer: a tecnocolonialidade a meu ver do/no corpo na arte, na cultura e na Educação aqui em debate, de agora em diante, tem a ver com aquela questão da epígrafe de Quijano - de que há uma crise que é ressaltada aos corpos latinoamericanos pela sua mais antiga história pós-colonial; genocídios, escravização, colonialismo -, mas, na atualidade, está imperante nesses corpos Latinos (e latino aqui engloba toda a má sorte de sujeitos não-europeus, por exemplo, que desgraçam na exterioridade ao projeto moderno europeu) que não são respeitados pela colonialidade do poder globalizante da tecnologia que finge incluir quando, na verdade, especialmente no caso brasileiro, mata pela exclusão ou submete o corpo à racialização e construção do outro como ser etnográfico, na produção artística, na cultura e na produção de conhecimentos para manutenção dos padrões históricos e contemporâneos (geo, ego e políticos) de poder. Igualmente, toda essa 
questão última é indissociável das políticas econômica da morte e de ódio bolsominians porque, atualmente, são essas que fazem a manutenção e perseverança daquelas antigas políticas e padrões coloniais. Assim, tecnocolonização vai estar para a colonização histórica do Ocidente, enquanto tecnocolonialidade vai fundar-se, nesta discussão, a partir de corpos da exterioridade que estão situados em Mato Grosso do Sul (Brasil - América Latina) - lugar geográfico de tríplice fronteira internacional, mas lóci de multíplices fronteiras culturais, sociais, políticas e epistemológicas internas - meu lócus de enunciação biogeográfico. Neste contexto as coias parecem não ter fim: ora, graças aos enunciados do desgoverno, as coisas se desorientam minando mais assuntos; ora, graças às tecnologias, os assuntos são insuflados pelos mesmos enunciados do desgoverno, mas também são evidenciados pelas mídias, pelas leis ou pelos compatriotas e contrários ao desgoverno. Nesses casos, para dar prosseguimento ao Desabafo-Manifesto-Denuncia aqui em construção - haja vista que a pandemia, desgraçadamente parece que vai continuar insuflando os vários problemas, primeiro, óbvio, de saúde, mas também políticos porque há um descontrole do desgoverno da situação pandêmica - vou tratar de alguns dos pontos agora elencados: tecnologias, mídias, leis, políticos compatriotas e dos contrários também. Para tanto, agora, por último, a liberação em 22 de maio pelo jurista e magistrado brasileiro José Celso de Mello Filho, ministro do Supremo Tribunal Federal, da integra da reunião de ministros de 22 de abril, mostra a milícia desgovernamental sob a qual estamos obrigatoriamente subjugados. De palavrões a palavras de baixo calão, o vídeo da reunião mostra um despresidente e seus comparsas em uma reunião de desgovernança por meio de um governo que sobrevive baseado no ódio e por uma política econômica da morte. Além de nos evidenciar, claramente, uma política de genocídio contra os "indígenas" e à Natureza, bem como vim mostrando antes nesta denúncia, querendo atravessar, "sob os panos" aos olhos das leis brasileiras, "uma boiada" de infrações; mostrou também uma política de ódio e preconceito indefinível e inigualável - já que é de um desministro da Educação - em relação aos "povos indígenas" termo que, aliás, o senhor Ministro faz questão de reforçar mais de uma vez o seu ódio em relação aos "povos" originários brasileiros; evidenciou uma política, por vias do mesmo Ministro da Educação, de ódio contra quem persevera para a manutenção e cumprimento das leis até para aqueles que se sentem acima delas, pedindo a prisão daqueles como se eles fossem ladrões; pairou na reunião uma política da ignorância, por meio da Ministra da Mulher, da Família e dos Direitos Humanos 
Damares Alves - como se esse desgoverno até tivesse um ministério dessa natureza - anunciando a prisão de governadores e prefeitos que, graças a ninguém sabe o que de fato, são os únicos que cuidaram/cuidam das suas respectivas populações preservando as suas vidas contra a pandemia do novo coronavírus, COVID-19, aquela, por sua vez, insistindo na realização e prestação de contas do seu desministério ao ditador mor. Logo, o que se viu ali, na pessoa do despresidente, na totalidade, foi o reforço da política do ódio. Mas nela volto daqui a pouco. Agora, é preciso demonstrar por onde passou a efetividade da política da economia da morte na reunião do desgoverno Bolsonaro:

Paulo Guedes: Duzentos e cinquenta. Tá certo? Então ó, tem cem bilhões vindo pra saneamento. Tinha cem bilhões que viriam, as dezessete maiores é ... é ... é ... petroleiras do mundo viriam pra a nossa cessão onerosa, cem bilhões de cessão onerosa, cem bilhões de mineração, cem bilhões de saneamento, duzentos trinta bilhões de concessões. Quinhentos bilhões! Cadê o dinheiro do governo pra fazer isso? Num tem. Então quem tá sonhando, é sonhador. A gente aceita, politicamente a gente aceita. Vamos fazer todo o discurso da desigualdade, vamos gastar mais, precisamos eleger o presidente. Mas o presidente tem que pensar daqui a três anos. Não é daqui a um ano não. Tem muita gente pensando na eleição desse ano. É só a observação que eu faria (apud UOL, 2020, online, grifos do site).

A fala do então Ministro da Economia - vai que ele também cai né? - demonstra a preocupação maior do desgoverno em relação à política da morte que prefere à economia que mata à vida das pessoas que morrem pela COVID-19. Apesar de recortado o assunto do diálogo, a conversa girava em torno do novo plano do desgoverno, que ainda não teve sua totalidade sancionada pelo despresidente (mas que teve a tentativa de ludibriar governadores na última quinta-feira, dia 21 de maio), para "salvar" os Estados e Municípios que estão em grande crise por causa da pandemia. Naquela ocasião, os ministros e o presidente debatiam as matérias que circulavam na mídia comparando o plano da Casa Cívil com um plano já fracassado, com o qual Paulo Guedes não concordava por contar com recursos do Governo Federal. Logo, vê-se que, ainda que com o País totalmente em crise em virtude da pandemia, o desministro da economia prefere defender a economia da morte às vidas que morriam pela COVID-19 falsamente dizendo que fariam "o discurso da desigualdade", gastando mais, mas porque precisavam se preocupar mais em "eleger o presidente". Assim, Guedes é, a personificação da política econômica da morte do desgoverno Bolsonaro porque desqualifica o funcionalismo público, quer vender todo o país para o capital privado, inclusive bancos e empresas que dão lucro para os cofres públicos, defende os grandes e 
mega empresários e bancos privados, alem de outras coisas que o colaca nas cabeças mentoras dessa política que assassina, diariamente, corpos pela COVID19, mas também de fome, sem trabalho, sem educação, sem direito a cultura, à arte e pior, que seus conhecimentos e subjetividades são desconsiderados: pois inexistem para esse indivíduo que se diz ministro da economia. Já sobre a política do ódio, encabeçada pelo líder máximo da desgovernança brasileira, o despresidente "falso messias", vê-se, na referida reunião, que seu desejo é o de ficar acima de todos e de tudo, inclusive do seu Deus e das leis. Pois, Ele, claramente, nem vou tratar da relação dele com o seu ex-quase-tudo - Sérgio Fernando Moro, que saiu defendendo sua biografia, é um jurista, ex-magistrado e professor universitário. Foi juiz federal, professor de direito processual penal na Universidade Federal do Paraná e ex-ministro da Justiça e Segurança Pública do Brasil do atual desgoverno - demonstra no vídeo da fatídica reunião que quer se colocar sobre a lei, sobre tudo e todas, resgatando artigos dela (a lei) que possam colocar em dúvida a credibilidade do decano do STF e a sua própria superioridade da lei igual para todos. Por último, enquanto continua tudo isso, a pandemia não vai passar tão facilmente assim como todos os desgovernos existentes no mundo pensaram, sábios foram os governantes que acreditaram rapidamente nela e que viram que a salvação de vidas era muito mais importante e inquestionável do que salvar as economias. Sabias palavras eram e continuam sendo as suas ex-Ministrio da Saúde brasileiro: "Mandetta: 'Quem é de direita usa cloroquina. Quem é de esquerda, tubaína. E quem é de juízo, escuta a medicina"” (apud MENDONÇA, 2020, online).

\section{Referências}

AGÊNCIA BRASIL. Educação. "Ministério da Educação adia o Enem 2020". Publicado em 20/05/2020 - 15:58 Por Agência Brasil - Brasília. Disponível em: https://agenciabrasil.ebc.com.br/educacao/noticia/2020-05/ministerio-da-educacao-adiao-enem-2020. Acesso em: 26 mai. 2020.

ANDRADE, Fabiano. "Teich deixa o Ministério da Saúde antes de completar um mês no cargo e após divergir de Bolsonaro". TV Globo, Brasília, 15/05/2020, 12h02. Disponível em: https://g1.globo.com/politica/noticia/2020/05/15/teich-deixa-o-ministerio-da-saudeantes-de-completar-um-mes-no-cargo.ghtml. Acesso em: 24 mai. 2020.

ARAÚJO, Ernesto. "Chegou o Comunavírus". BLOG Metapolítica 17 - contra o globalismo. 21 de abril de 2020. Disponível em: 
https://www.metapoliticabrasil.com/post/chegou-o-comunav\%C3\%ADrus. Acesso em: 26 mai. 2020.

BESSA-OLIVEIRA, Marcos Antônio. “(Des)política para corpos-política na arte, na cultura e na educação". Interritórios: Revista de Educação, v. 6, n. 10, Universidade Federal de Pernambuco, Caruaru, Brasil, 2020, p. 1-26. Disponível: https://periodicos.ufpe.br/revistas/interritorios/article/view/244891/0. Acesso em: 24 mai. 2020.

BESSA-OLIVEIRA, Marcos Antônio. O corpos das artes (cênicas) latinas ainda é razão e emoção!: "Quando essa porra toda explodir, aí Eu quero é ver!”. Cadernos de Estudos Culturais: Corpos Epistêmicos, v. 2 n. 22, jul./dez., Campo Grande, MS: 2019, p. 83-109. Disponível em: https://periodicos.ufms.br/index.php/cadec/article/view/9711. Acesso em: 15 mai. 2020.

BESSA-OLIVEIRA, Marcos Antônio. O corpo das artes (cênicas) latinas ainda é razão e emoção!. Anais do Simpósio Reflexões Cênicas Contemporâneas, 2019a. Disponível em: https://www.cocen.unicamp.br/revistadigital/index.php/simposiorfc/article/view/636.

Acesso em: 15 mai. 2020.

BRAGANÇA, Daniele. "Bolsonaro promete a garimpeiros que vai rever norma sobre queima de máquinas". O Eco. Terça-feira, 5 novembro 2019, 16:21. Disponível em: https://www.oeco.org.br/noticias/bolsonaro-promete-a-garimpeiros-que-vai-rever-normasobre-queima-de-maquinas/. Acesso em: 26 mai. 2020.

COFEN - Conselho Federal de Enfermagem. "Brasil ultrapassa EUA em mortes de profissionais de Enfermagem por Covid-19". 08/05/2020. Disponível em: http://www.cofen.gov.br/brasil-ultrapassa-eua-em-mortes-de-profissionais-deenfermagem-por-covid-19 79624.html. Acesso em: 26 mai. 2020.

CORREIO 24 HORAS. “Coronavírus”. Redação, 20.04.2020, 22:14:00. Disponível em: https://www.correio24horas.com.br/noticia/nid/nao-sou-coveiro-ta-diz-bolsonaro-aoresponder-sobre-mortos-por-coronavirus/. Acesso em: 25 mai. 2020.

COSTOLLI, Anderson; TESTI, Fabiola. ““'Sempre houve tortura”, diz Regina Duarte, minimizando a ditadura”. Metrópoles. 07/05/2020, 18:30. Disponível em: https://www.metropoles.com/brasil/sempre-houve-tortura-diz-regina-duarteminimizando-a-ditadura. Acesso em: 25 mai. 2020.

DW - Brasil. "Queimadas no Brasil aumentam 82\% em relação a 2018”. Disponível em: https://www.dw.com/pt-br/queimadas-no-brasil-aumentam-82-emrela\%C3\%A7\%C3\%A3o-a-2018/a-50092662. Acesso em: 26 mai. 2020.

FERNANDES, Augusto. ““O maior remédio pra qualquer doença é o trabalho”, diz Bolsonaro". Correio Braziliense - Política. 27/03/2020 23:56. Disponível em: 
https://www.correiobraziliense.com.br/app/noticia/politica/2020/03/27/interna politica,84 0821/o-maior-remedio-pra-qualquer-doenca-e-o-trabalho-diz-bolsonaro.shtml. Acesso em: 26 mai. 2020.

FERRO, Maurício. “"Vai morrer gente? Vai morrer gente”, diz Bolsonaro sobre a covid19”. Poder 360. 30.mar.2020 (segunda-feira) - 11h20. Disponível em: https://www.poder360.com.br/governo/vai-morrer-gente-vai-morrer-gente-diz-bolsonarosobre-a-covid-19/. Acesso em: 26 mai. 2020.

G1. "Ao menos 76 profissionais de enfermagem morreram em decorrência da Covid-19 no Brasil, segundo conselho da categoria". 06/05/2020. Disponível em: https://g1.globo.com/bemestar/coronavirus/noticia/2020/05/06/ao-menos-76-enfermeirosmorreram-em-decorrencia-da-covid-19-no-brasil.ghtml. Acesso em: 26 mai 2020.

JORNAL ESTADO DE MINAS. Educação. "Realização do Enem em 2020 está garantida, diz ministro da Educação". Agência Brasil, postado em 17/04/2020 22:34. Disponível

em:

https://www.em.com.br/app/noticia/educacao/2020/04/17/internas_educacao,1139830/rea lizacao-do-enem-em-2020-esta-garantida-diz-ministro-da-educacao.shtml. Acesso em: 26 mai. 2020.

MBEMBE, Achille. "Necropolítica: biopoder soberanía estado de exceção política da morte". Arte \& Ensaios - revista do ppgav/eba/UFRJ, n. 32, dezembro, 2016, p. 123-151. Disponível em: https://revistas.ufrj.br/index.php/ae/article/view/8993. Acesso em: 09 mai. 2020.

MENDONÇA, Ana, "Mandetta: 'Quem é de direita usa cloroquina. Quem é de esquerda, tubaína. E quem é de juízo, escuta a medicina"”. JORNAL ESTADO DE MINAS. Política.

Disponível

em: https://www.em.com.br/app/noticia/politica/2020/05/20/interna_politica,1149148/mandet ta-direita-usa-cloroquina-esquerda-tubaina-juizo-medicina.shtml. Acesso em: 26 mai. 2020.

MIGNOLO, Walter. D.. COLONIALIDADE: O lado mais escuro da modernidade. Tradução de Marco Oliveira. Revista Brasileira de Ciências Sociais, vol. 32 no. 94, São Paulo, Epub June 22, p. 1-18, 2017. Disponível em: https://www.scielo.br/scielo.php?script=sci_arttext\&pid=S010269092017000200507\&lng=en\&nrm=iso\&tlng=pt. Acesso em: 16 mai. 2020.

MIGNOLO, Walter. Desafios decoloniais hoje. Trad. de Marcos de Jesus Oliveira. Epistemologias do Sul: Pensamento Social e Político em/desde/para América Latina, Caribe, África e Ásia, v.1, n. 1, Foz do Iguaçu/PR: Universidade Federal da Integração Latino-Americana, p. 12-32. 2017a. Disponível em: 
https://revistas.unila.edu.br/epistemologiasdosul/article/view/772/645. Acesso em: 27 mar. 2018.

MOTA, Erick. "Bolsonaro sobre coronavírus: "Alguns vão morrer, lamento, essa é a vida"”. Congresso em foco. 28 mar, 2020 - 11:07. Disponível em: https://congressoemfoco.uol.com.br/governo/bolsonaro-sobre-coronavirus-alguns-vaomorrer-lamento-essa-e-a-vida/. Acesso em: 25 mai. 2020.

PRESIDÊNCIA DA REPÚBLICA. Planalto. "Pronunciamento do Senhor Presidente da República, Jair Bolsonaro, em cadeia de rádio e televisão". Publicado em 24/03/2020, 21h25. Atualizado em 31/03/2020, 21h14. Disponível em: https://www.gov.br/planalto/pt-br/acompanhe-oplanalto/pronunciamentos/pronunciamentos-do-presidente-da-republica/pronunciamentoem-cadeia-de-radio-e-televisao-do-senhor-presidente-da-republica-jair-bolsonaro. Acesso em: 24 mai. 2020.

QUIJANO, Aníbal. La americanidad como concepto, o América en el moderno sistema mundial. Revista Internacional de Ciencias Sociales. América: 1492-1992. Trayectorias históricas y elementos del desarrollo. Organización de las Naciones Unidas para la Educación, la Ciencia y la Cultura con la colaboración de la Comisión Española de Cooperación con la UNESCO y del Centre UNESCO de Catalunya. Vol. XLIV, núm. 4, Diciembre, 1992, p. 583-591. Disponível em: https://unesdoc.unesco.org/in/documentViewer.xhtml?v=2.1.196\&id=p::usmarcdef_0000 092855_spa\&file=/in/rest/annotationSVC/DownloadWatermarkedAttachment/attach_imp ort_75bfd895-8b09-4c59-ba1b-

be3c036a6d11\%3F \%3D092855spao.pdf \&locale=en\&multi=true $\&$ ark=/ark:/48223/pf00 00092855_spa/PDF/092855spao.pdf\#\%5B\%7B\%22num\%22\%3A447\%2C\%22gen\%22\% 3A0\%7D\%2C\%7B\%22name\%22\%3A\%22XYZ\%22\%7D\%2Cnull\%2Cnull\%2C0\%5D.

Acesso em: 09 mai. 2020.

QUIJANO, Aníbal. Aníbal Quijano: ensayos en torno a la colonialidad del poder. Compilado por Walter Mignolo. $1^{\text {a }}$ ed.. Ciudad Autónoma de Buenos Aires: Del Signo, 2019. (El desprendimiento / Mignolo, Walter).

RODRIGUES, Larissa; BESSA-OLIVEIRA, Marcos Antônio. O CORPO PRIMITIVO CONTEMPORÂNEO DA/NA MARGEM NÃO TECNO(LÓGICA). Trabalho de Conclusão de Curso. Curso de Artes Cênicas - Licenciatura, UEMS - Universidade Estadual de Mato Grosso do Sul, 2019a, p. 1-24. Disponível em: http://www.uems.br/assets/uploads/cursos/81f7af02b1a7a7e7107b971c31ea3b4c/tcc/1_81 f7af02b1a7a7e7107b971c31ea3b4c 2019-12-13 16-15-08.pdf. Acesso em: 20 mai. 2020.

SHALDERS, André. "Mandetta é demitido do Ministério da Saúde após um mês de conflito com Bolsonaro: relembre os principais choques". BBC News Brasil, Brasília, 16 
abril 2020. Disponível em: https://www.bbc.com/portuguese/internacional-52316728. Acesso em: 24 mai. 2020.

UOL. "Chanceler brasileiro diz que mundo enfrenta "comunavírus"”. ANSA. 22/04/2020, 09h40. Disponível em: https://noticias.uol.com.br/ultimasnoticias/ansa/2020/04/22/chanceler-brasileiro-diz-que-mundo-enfrenta-comunavirus.htm. Acesso em: 26 mai. 2020.

UOL. Política. "Leia a íntegra da reunião ministerial de 22 de abril". São Paulo, 22/05/2020, 18h38. Disponível em: https://noticias.uol.com.br/politica/ultimasnoticias/2020/05/22/confira-a-integra-da-degravacao-da-reuniao-ministerial-de-22-deabril.htm. Acesso em: 26 mai 2020.

URIBE, Gustavo; CARVALHO, Daniel. "Bolsonaro: "Quem é de direita toma cloroquina, quem é de esquerda, Tubaína"'. Capa NSC Total Saúde. PROTOCOLO DE SAÚDE. 20/05/2020 - 05h05. Disponível em: https://www.nsctotal.com.br/noticias/bolsonaro-quem-e-de-direita-toma-cloroquinaquem-e-de-esquerda-tubaina. Acesso em: 25 mai. 2020.

VIDA E AÇÃO. "Número de mortes por Covid-19 dobra a cada 5 dias no Brasil". Redação, 26 de abril de 2020. Disponível em: https://www.vidaeacao.com.br/numero-demortes-por-covid-19-dobra-a-cada-5-dias-no-brasil/. Acesso em: 24 mai. 2020.

Artigo recebido em: 30 de março de 2020. Artigo Aprovado em: 29 de setembro de 2020. 